UDK

Josef Malach, Kateřina Kostolányová, Milan Chmura, Ingrid Nagyová, Tatiana Prextová, Pedagogical Faculty, University of Ostrava, Ostrava, Czech Republic

\title{
THE CONCEPTUAL BASES FOR DESIGNING MODULE "TOOLS FOR ADAPTIVE LEARNING AND LEARNING STYLES" WITHIN MOOC COURSE "ICT TOOLS FOR E-LEARNING"
}

\begin{abstract}
The study presents a short overview of the development of the adaptive learning concept, shows its contribution to effective learning and teaching and introduces trends of its further development which - in the form of adaptive e-learning - are related to the use of the everdeveloping ICT. It also presents the current ICT system tools. Furthermore, it provides information about the research and design results of the "Ostrava School" of adaptive e-learning. The results, together with a number of other inputs, will provide the content framework for the specialized educational module "Tools for Adaptive Learning and Learning Styles" within the MOOC course "OCI Tools for E-leaning", which is being developed as an output of the IRNET international project.
\end{abstract}

Keywords: adaptive learning, adaptive instruction, learning styles, adaptive learning tools, adaptive learning systems, intelligent adaptive learning, adaptive educational hypermedia systems

Introduction. Due to the development of ICT, adaptive learning, which takes into account individual learners' needs, is changing. Learners' learning styles are one of the most significant characteristics. They can be categorized according to a number of criteria which are based on cognitive and emotional components of personality. Their combination leads to the countless individual variants of real learning methods which - to a certain degree - can be influenced by the current e-learning resources. When the e-learning resources can react to the learners' input characteristics or their learning results, they become adaptive e-learning systems (AES) or intelligent AES.

If these systems are used for evaluating learning outputs, they become adaptive assessment systems (AAS). With the technical, personnel and research background, universities can not only use both AES and AAS, but also realize their experimental verification and implementation into education.

That is why at the University of Ostrava a team of experts is developing the module "Tools for Adaptive Learning and Learning Styles" within the MOOC course "OCI Tools for E-leaning", which should help both the observers and creators of AES and AAS - particularly the future teachers at all school levels (from university teachers to adult educators) - learn how to use and implement them effectively. The course should provide conceptual knowledge, information about the trends and development of adaptive learning, adaptive elearning tools, the results achieved by its application and skills necessary for the practical use of the systems and evaluation of its effects.

\section{Adaptive E-learning Development and Implementation}

In the late 1950s, Gordon Pask introduced the idea of instruction with the use of educational machines. As he thought it could be realized through the conversation theory and game theory, he created adaptive educational programs.

After the era of disinterest in the ideas of adaptive learning which was associated mainly with the overall state of the movements promoting and realizing different concepts of personalized learning, there is a revival that is a result of the updates in the area of ICT. The second important factor is the development in knowledge of learning styles, cognitive styles, approaches to study, learning habits and learning modes.

The beginning of the $21^{\text {st }}$ century is seeing the rise of the so-called Intelligent Adaptive Learning (IAL), which serves to individualize and, to some extent, personalize learning for 
each student. Intelligent adaptive learning is defined as digital learning that immerses students in modular learning environments where every decision a student makes is captured, considered in the context of the sound learning theory, and then used to guide the student's learning experiences, to adjust the student's path and pace within and between lessons, and to provide formative and summative data to the student's teacher. This type of learning tailors instruction to each student's unique needs, current understandings, and interests, while ensuring that all responses subscribe to sound pedagogy. The IAL System are designed a) To serve as a personal tutor to the student b) Adapt the sequencing of the curriculum and associated learning experiences c) Individualize the pace of learning d) Regulate cognitive load for the student e) Engage students in learning through gaming (Dreambox, 2011). The adaptive program Dreambox which is being developed in the U.S.A. and Great Britain is showing promising results (WWC Intervention Report, 2013, Harvard university, 2016).

According to the latest NMC Horizon Report (2016), "Learning Analytics and Adaptive Learning" should become a development trend in the area of the implementation of educational technologies at universities within a year.

"Learning analytics is an educational application of web analytics aimed at learner profiling, a process of gathering and analyzing details of individual student interactions in online learning activities. The goal is to build better pedagogies, empower active learning, target at-risk student populations, and assess factors affecting completion and student success. Adaptive learning technologies apply learning analytics through software and online platforms, adjusting to individual students' needs. A paper by Tyton Partners describes adaptive learning as a "sophisticated, data-driven, and in some cases, nonlinear approach to instruction and remediation, adjusting to a learner's interactions and demonstrated performance level, and subsequently anticipating what types of content and resources learners need at a specific point in time to make progress. In this sense, contemporary educational tools are now capable of learning the way people learn. Enabled by machine learning technologies, they can adapt to each student in real time"'(p.38).

The paper by Tyton Partners (2016), which deals with the development of adaptive learning in the university environment (see the definition of adaptive learning above), contains interesting information about evaluating current e-learning products. It summarizes the reasons why universities should change their approach to instruction and implement the products. This will lead to the instruction becoming:

1. Active, insofar as it uses technology to add focus to the role of faculty as instructors who shape the "journey" and outcomes of learning.

2. Relational, as faculty is empowered to work as subject matter experts, coaches, and guides alongside students who are progressing through an adaptive curriculum or assessment

3. Involved through the use of digital features and functions that enable faculty to direct learners through a module, course, or program and to stage interactions and interventions as needed

4. Insightful at scale through the use of analytics, dashboards, and learning maps that provide faculty with greater transparency into student progress, and the use of indicators or flags to suggest potential interventions to improve the likelihood of student success.

The report also contains recommendations for new users of adaptive systems and the description of 20 systems (platforms) which can be used.

A number of impulses motivating universities and academics to use the adaptive learning and teaching systems are based on the annual IMS Global Learning Consortium reports. In the 2013 report, adaptive learning, online homework and formative assessment were placed $3^{\text {rd }}$ in a two-dimensional matrix (Implementation Challenges and Learning Impact Gain/Potential) with the following assessment: "Clearly superior", 
"Straightforward/Turnkey", respectively. That means the authors see great potential in adaptive learning.

The 2015 report (IMS Global, 2016) lists three new Learning Impact Trend categories, which among others include the element of personalized learning. These are a) Integrated Digital Curriculum to Enable Student-Centered Learning underscores new ways to manage an array of curated digital content and tool alternatives; b) Assessment Enhancements with Digital Technology marks the growing proliferation of technology-based tools and applications to assess student performance and learning outcomes; c) Educational Accessibility and Personalization highlights technology's increasing ability to enhance all students' learning experiences, including those with physical and learning disabilities.

Determining the trends in the implementation of ICT into education, i.e. the development of adaptive e-learning, is based on the results of conducted experiments.

Although Beckman, Bertel and Zander (2015) did not found statistically important impact of the instruction adapted to the student's preferred learning style on the verbal and visual areas, they found out that it influences emotional factors such as motivation and satisfaction. Emotional factors should not be underestimated as they play a substantial role in self-regulated learning.

Surjono (2015) studied the effects of instruction in an adaptive system which could realize instruction based on the combination of the learning style and preferred multimedia. He named the system the "learning mode". He found out that the students who used a particular learning mode achieved better results than those who used the system which did not contain "their" mode on three successive occasions.

At the end of their study aimed at the comparison of adaptive and traditional instruction, Murray and Pérez state that ,adaptive learning is touted as a potential game-changer in higher education, a panacea with which institutions may solve the riddle of the iron triangle: quality, cost, and access. Though the research is scant, this study and a few others like it indicate that today's adaptive learning systems have negligible impact on learning outcomes, one aspect of quality. There is also evidence that adaptive systems positively impact other aspects of quality such as student persistence and engagement".

In their study, Huang a Shiu (2012) confirmed the practicability of user-centric adaptive learning (UALS), which employs users' collective intelligence to generate adaptive learning paths and select materials, which makes it comparable to a teaching expert. Students' learning performances in Group 2 and 3 were not different to that in Group 1. This study also found that learners have more satisfaction and learning efficiency from user-centric adaptive learning. Students in Group 1 did not perceive the improvement of their knowledge levels, and the lengths of learning paths in Group 1 were significantly longer than those in Groups 2 and 3. The research results reveal that users may have different notions from an expert in concepts and learning orders; and an expert tends to overestimate learners' knowledge levels when choosing learning materials. Since a gap exists between experts' and learners' views, and learners can easily share their knowledge in the e-learning 2.0 environment, applying collective intelligence to provide formal and direct learning services for the learners is more promising and important in the future learning environment.

(Note: Group 1: Traditional e-learning that uses expert-defined learning paths and content-Users study through the learning paths and browse the materials that are pre-defined by an instructor.

Group 2: User-centric and adaptive learning path with expert-defined content-Users study the course following the user-centric learning paths determined by the adaptive navigation mechanism, but the material of each learning node is decided by the instructor. 
Group 3: Complete user-centric adaptive learning-Users study the course following the learning paths determined by the adaptive navigation mechanism, and the materials of each learning mode are determined by the adaptive presentation mechanism.)

\section{Approach to Adaptive E-learning at University of Ostrava}

Educational environment is considered adaptive when it can monitor and interpret activities of the users, determine users' requirements and preferences on the basis of the interpreted activities and dynamically adapt the education process.

The LMS Barborka is a system created at the University of Ostrava which can adapt the content of instruction to different learning styles of students and works with a detailed study material divided into sections. The author of the course creates the study material in a number of sensory forms and difficulty levels. The instruction itself is managed by an algorithm the parameters of which are set by an expert on adaptive education. The system is divided into the Student, Author and Expert modules.

\section{Author Module}

This module contains adaptive study materials. Each course is divided into units, frames, variants and layers. Using forms, the author inserts the content of instruction into the system as a formatted text with added metadata. The author only creates the content of instruction, they have no power over the way of adaptation.

\section{Student Module}

This module is aimed at collecting information about the student, i.e. determine their learning style and monitor and evaluate the course of their instruction. The student's learning style is determined through a questionnaire. Furthermore, this module monitors the course of the student's instruction, particularly the time spent on the individual parts and the level of correctness of their answers. During instruction, the system offers the student the material that best corresponds to their learning style. However, the student still can adapt the displayed material to their own needs, i.e. if they are not satisfied with the optimal variants, they can select a different sensory form or depth of instruction. The system monitors and records the changes made by the student and all the other activities.

\section{Expert Module}

This module defines the actions of the so-called Virtual Teacher, i.e. a program that displays suitably sequenced parts of the study material in a suitable variant to a student with given characteristics. The Virtual Teacher operates on the basis of a set of rules proposed by an expert on adaptive instruction. Each rule consists of assumptions and conclusions, with "assumption" being the level of the student's characteristics and "conclusion" being the depth of the individual layer types and the sensory type of the displayed frame.

The system uses two algorithms:

- Algorithm of adaptive selection of teaching style

On the basis of rules, this algorithm creates a recommended teaching style for each student (specifies sensory variants, defines sequence and depth for parts of the study material).

- Algorithm of adaptive learning management

On the basis of the determined learning style, this algorithm selects and displays specific parts of the study material. Moreover, the algorithm manages the reaction of the system to the student's incorrect answer.

The expert rules used in both algorithms are of the IF - THEN type. They represent "pedagogical experience, knowledge and skills" in managing personalized education (Kostolányová, 2012).

\section{Ostrava}

Selected Approaches to Adaptive E-learning System Solutions at University of

A number of Ph.D. students studying in the ICT in Education study program who deal with partial problems of adaptive education in their dissertations are a part of the team of 
experts focusing on the research of adaptive education at the University of Ostrava. Therefore, the theory of adaptive e-learning is gradually being verified in practice and expanded by the results of related researches. A number of successfully defended Ph.D. dissertations were aimed at the following partial issues in the field of adaptive education:

- Proposing the system of adaptive revision and electronic testing, experimental verification of the proposed system and determining whether the new form of revision helps improve the level of knowledge. Feedback (for both students and teachers) in the form of detailed information which describes their shortcomings, leads to the improvement in the tested area (in an adaptive way based on the student's results) and motivates them to study and achieve better results. It helps teachers to improve their performance.

- Proposing the optimized model for the teaching of a foreign language at a university; adaptation of the study material to individual students based on the determined learning style.

- Proposing adaptive rules reflecting specifics of the foreign language instruction in adaptive e-learning and creating an adaptive study material for the teaching of a foreign language in a number of variants. Verify in an experimental manner whether there is a positive relation between effective learning and individualized instruction within the scope of the autonomous instruction of a foreign language in e-learning.

- The goal of another dissertation was to create and verify an ICT-supported individual model for the teaching of the English language with regard to the student's sensory characteristics. The issue was approached by comparing the habit - the way in which the student had been learning the foreign language up to then - with their sensorimotor preferred learning style. The assumption that the students who followed their existing learning habit would achieve better results was confirmed in the area "reading with understanding". In this case, better results are knowledge tested immediately after the instruction and then again after another 3 months. This way the level of sustainability of knowledge both with and without hindsight is determined.

- Two dissertations dealt with the issue of evaluation. Each used a different method and evaluated different facts. In the dissertations, two new methods of automatic evaluation were proposed and tested.

The first original method can partially replace a didactic review written before the start of instruction according to the created study material. It is based on the use of a semantic network of terms which is automatically created above the study material. The semantic network provides information about relations between terms of different types, which are determined and recorded. The relations are further used for determining whether the study material does not violate any of the basic didactic principles.

The second method automates the analysis of the education process protocol. It uses the actual behavior of students during instruction (recorded in detail) to statistically calculate various characteristics and find the previously unknown associations between the attributes of the education process. To achieve that, it uses data mining.

All of the abovementioned topics have been tested through the proposed adaptive system Barborka LMS (mostly through a pedagogical experiment) on a sufficient number of pupils or students (there were hundreds of them) at elementary schools, high schools or universities. Following the evaluation, the results and recommendations are gradually implemented into the Barborka LMS.

Conclusion. Preparation of the syllabus of the study module and its transformation into online study materials, which will include short thematic video sequences, control tests and the final test, requires its authors to have deep knowledge of the fundamental pedagogical 
and technological aspects of adaptive e-learning. That is why the particular theoretical concepts and research results, which will become a curricular material necessary for achieving goals of the course in all of the target domains, are analyzed and processed. At universities, this is, for many reasons, a desirable trend which should reduce doubts about the effects and effectiveness of digital education in the broadest sense.

Those who take this MOOC module can become better researchers or users in that particular area. They can become better university (or other) teachers but also, and mainly, better students who will better understand the functions and possibilities of adaptive elearning systems and thus will want to use them more.

The paper describes the authors' effort to present the issue of adaptive e-learning to the students of the module from a variety of viewpoints, particularly from the psychological, pedagogical and technological viewpoints. The audiovisual presentation of the curriculum, the use of feedback and presentation of the content in an interesting manner, which will be achieved through the use of historical and comparative information and the author's own experience with designing and using adaptive e-learning systems used at the University of Ostrava, seem to be potentially suitable didactic tools for the practical implementation of the course.

Acknowledgments. The research leading to these results has received, within the framework of the IRNet project, funding from the People Program (Marie Curie Actions) of the European Union's Seventh Framework Program FP7/2007-2013/ under REA grant agreement No: PIRSES-GA-2013-612536

\section{REFERENCES}

Beckmann, J., Bertel, S. \& Zander, S. Performance \& emotion -a study on adaptive elearning based on visual/verballearning styles. International Conference e-Learning, 2015, 2734.

Boyd, G. M. Conversation theory. in Jonassen, D.H. Handbook of Research on Educational Communications and Technology. Second Edition. Routlege, 2004, 179-197.

Czeczotková, B. \& Prextová, T. Creation of study materials for adaptive learning. Jounal of Technology and Information Education. 2014, vol. 6, iss. 1, 57-70.

Dreambox Learning. Leveraging Intelligent Adaptive Learning for Personalize Education. 2011. Available at: http://www.dreambox.com/white-papers/leveragingintelligent-adaptive-learning-to-personalize-education

Dream Box Learning. What Works Clearinghouse Intervention Report, (2013) Available at: https://eric.ed.gov/?q=adaptive+instruction+\&pg=2\&id=ED544506

Harward university. Key Findings Report. Dreambox Learning Achievement Growth. 2016. Available at: http://cepr.harvard.edu/dreambox-learning-achievement-growth

Huang, S.-L., \& Shiu, J.-H. A User-Centric Adaptive Learning System for E-Learning 2.0. Educational Technology \& Society, 2012, 15 (3), 214-225.

Chen, C.H. \& Chang, S.W. Effectiveness of adaptive assessment versus learner control in a multimedia learning system. Journal of Educational Multimedia and Hypermedia, 2015, 24(4), 321-341. Chesapeake, VA: Association for the Advancement of Computing in Education (AACE).

Chang, Y-H., Chen,Y-Y., Chen, N.-Sh., Lu, Y.-T. \& Fang, R.-I. Yet another adaptive learning management system based on Felder and Silverman's learning styles and Mashup. Eurasia Journal of Mathematics, Science \& Technology Education, 2016, 12(5), 1273-1285 doi: 10.12973/eurasia.2016.1512a 
Ikwumelu, S.N., Oyibe, O.A. \& Oketa, E. C. Adaptive Teaching: An Invaluable Pedagogic Practice in Social Studies Education. Journal of Education and Practice. 2015, Vol.6, No.33, P. 140-144.

IMS Global Learning Consortium. (2013) Learning Impact Report: e-Texts and Adaptive Learning Leading the Way to an Emerging World of Educational Apps. Available at:

http://www.imsglobal.org/sites/default/files/LIA/LIA2013Report.pdf

IMS Global Learning Consortium. Identifying and Understanding Pragmatic Trends in the Application of Technology to Improve Learning. Available at: https://www.imsglobal.org/event/2016-learning-impact-leadership-institute

Kostolányová, K. (2012). The theory of adaptive e-learning. Ostrava: University of Ostrava. ISBN 978-80-7464-014/8.

Murray, M. C., \& Pérez, J. (2015). Informing and performing: A study comparing adaptive learning to traditional learning. Informing Science: the International Journal of an Emerging Transdiscipline, 18, 111-125. Available at: http://www.inform.nu/Articles/Vol18/ISJv18p111-125Murray1572.pdf

NMC Horizon Report: 2016 Higher Education Edition. Available at: http://www.nmc.org/publication/nmc-horizon-report-2016-higher-education-edition/

Somyürek, S. The New Trends in Adaptive Educational Hypermedia Systems. International Review of Research in Open and Distributed Learning, Volume 16, Number 1 2015, 221-241.

Surjono, H. D. the effects of multimedia and learning style on student achievement in online electronics course. TOJET: The Turkish Online Journal of Educational Technology. 2015, vol 14 issue 1,116-121.

Šarmanová, J. et al. Metodika tvorby personalisovaných e-learningových opor. Ostrava, VŠB-TU, 2011.

Tyton Partners. Learning to adapt. The evolution of adaptive learning in higher education. (2016). Available at: http://tytonpartners.com/library/learning-to-adapt-2-0-theevolution-of-adaptive-learning-in-higher-education/

van Setters, J. R., Ossevoort, M. A., Tramper, J. \& Goedhart, M. J. The influence of the student characteristics on the use of adaptive e-learnig materials. Computers \&Education. 2012. vol 58, iss. 3, 942-952.

WWC Intervention Report What Works Clearinghouse. U.S. DEPARTMENT OF EDUCATION, 2013. Available at:

Verdú, E., Regueras, L. M., Verdú, M. L., De Castro, J.P., \& Pérez, M. A. An analysis of the Research on Adaptive Learning:The Next Generation of e-Learning. WSEAS TRANSACTIONS on Information science \& applications. Issue 6, Volume 5, June 2008

Yang, T.-C., Hwang, G.-J., \& Yang, S. J.-H. (2013). Development of an adaptive learning system with multiple perspectives based on students' learning styles and cognitive styles. Educational Technology \& Society, 16 (4), 185-200. 